\title{
CVO: Redução de gastos indica acerto da iniciativa
}

O governo federal economizou 19,191 milhões de cruzados durante o mês de junho, com a redução de 132 veiculos e 185 motoristas da frota oficial dos Ministérios do Interior, Indústria e Comércio, SEDAP, Agricultura, Transporte, Trabalho e Saúde. Essa economia é o resultado da implantação, em 31 de maio deste ano, da Central de Veículos Oficiais (CVO), pela Secretaria de Administração Pública da Presidência da República (SEDAP), visando racionalizar o uso dos carros of iciais no transporte dos servidores civis em Brasília.

\section{Como novo instrumento de racionalização dos gastos públicos, a implantação do CVO, até o final do ano vai atingir todos os ministérios}

Essas informaçōes fazem parte do relatório do primeiro mês de atuação da CVO, enviado ao ministro Aluizio Alves. Segundo o relatório, que compara a situação da frota oficial desses ministérios nos meses de janeiro e junho, a redução dos gastos (veja quadro) foi de $74,5 \% 25,746$ milhões de cruzados em janeiro contra, 6,555 milhões de cruzados em junho), causada pela diminuição de 180.907 quilômetros rodados no mês $\mathbf{2 6 9 . 9 9 4}$ $\mathrm{Km}$ em janeiro contra $89.087 \mathrm{Km}$ em junho). O desempenho da CVO no mês de junho impressionou o ministro Aluizio Alves: "Quando projetamos o serviço, a meta adotada previa uma economia mensal de até $15 \mathrm{mi}$ lhões de cruzados por isso esse resultado é surpreendente e demonstra que estamos no caminho certo".

\section{ORIGEM}

Estudos realizados pela própria SEDAP constataram uma ociosidade média de $85 \%$ dos veículos da frota oficial em Brasilia, e em conseqüência, de $94 \%$ dos motoristas (o número de motoristas é sempre maior que o de veículos, para garantir a operação da frota). Eram veiculos e funcionários estacionados nas garagens, sem um aproveitamento condizente com o investimento que representam. Partindo dessa constatação, o ministro Aluízio Alves baixou a Instrução Normativa n: 204, em janeiro deste ano, reduzindo a frota oficial dos órgãos da administração direta e indireta participantes do sistema de Serviços Gerais, para apenas 11 veículos, 2 para o ministro, 1 para o secretário- geral, 3 para serviços especiais e 5 para a frota de serviço do ministério. A instrução ministerial exclui a frota dos ministérios destinada à fiscalização e outros serviços essenciais.

Reduzida a frota oficial da administração federal em Brasília, foi criada a CVO, que aproveitando partes dos veiculos desativados, instituiu um "pool" para o transporte racional de servidores, acabando com a ociosidade dos carros oficiais.

Como instrumento novo de racionalização dos gastos públicos, decorrente da Reforma Administrativa desencadeada pelo Governo Federal, a implantação da CVO acontecerá em quatro etapas: a primeira, já implantada, atinge sete ministérios citados; a segunda, que deve ser iniciada até o final do ano, vai englobar os minis-

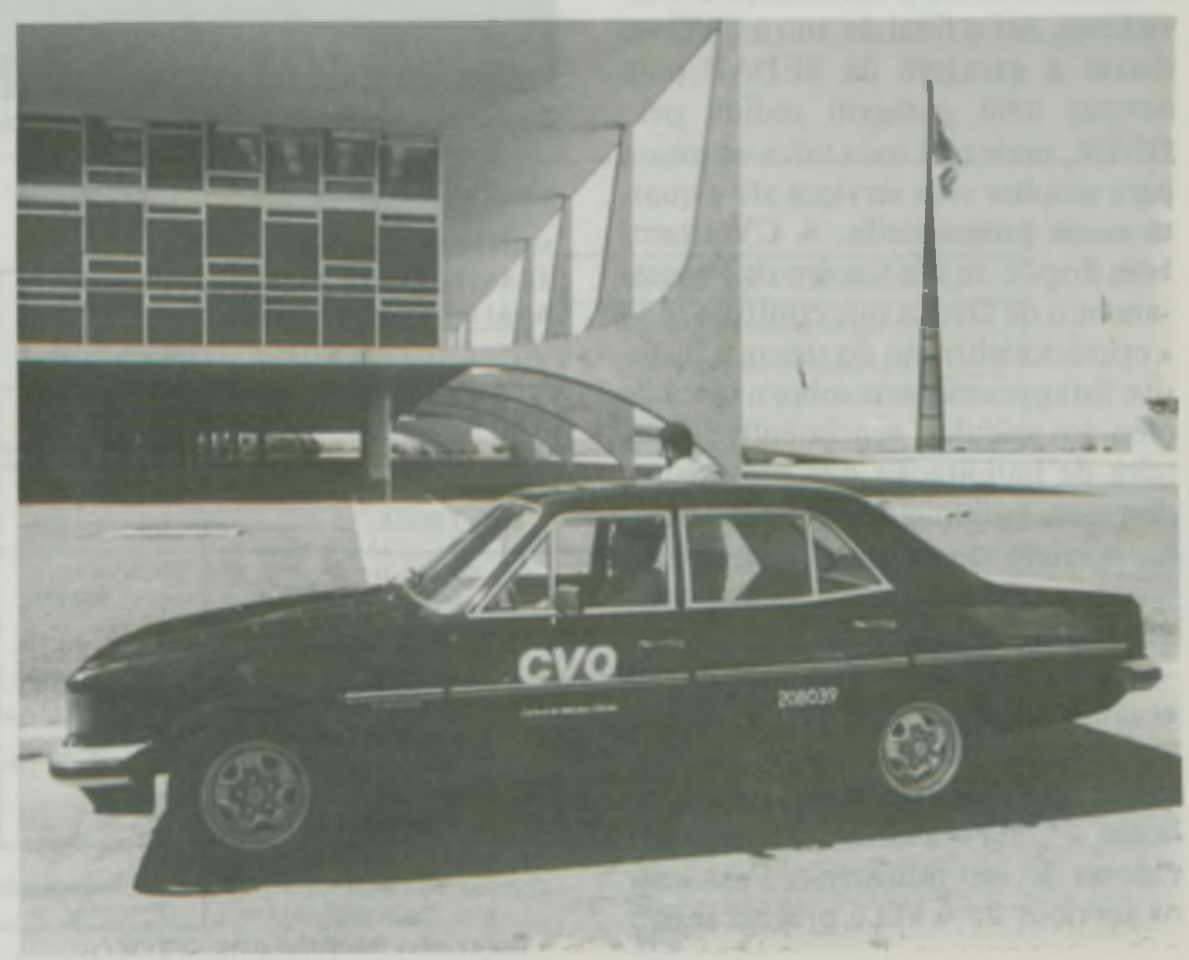

Veiculo da CVO deixa passageiro no local de destina. 


\section{NOTICIÁRIO}

térios da Ciência e Tecnologia, Comunicações, Cultura, Habitação Urbanismo e Meio Ambiente, Fazenda, Justiça, Educação, Minas e Energia, Previdência e Assistência Social, Reforma e Desenvolvimento Agrário e Relações Exteriores; na terceira fase serão incluídos os órgãos autônomos integrantes dos SISG (Sistema de Serviços Gerais); e na quarta etapa as autarquias.

\section{A grande estratégia está em que a cada chamada individual não corresponda ao deslocamento de um novo veículo}

\section{COMO FUNCIONA}

A CVO dispõe hoje, para operacionalizar a primeira fase do atendimento aos sete ministérios, de 40 veículos (Opala e Passat), 23 funcionários administrativos, 2 mecânicos e 4 lavadores. Até o final do ano a CVO vai deixar a garagem da SEDAP para ocupar uma garagem cedida pelo DNER, onde terá toda infra-estrutura para ampliar seus serviços até a quarta etapa programada. A CVO também dispõe de um Centro de Processamento de Dados que controla loda a operacionalização do sistema, inclusive listagens mensais sobre a troca de óleo dos veículos, vencimento da carteira de habilitação dos motoristas, despesas, quilometragem de cada carro, número de saídas diárias e seus motivos, além do número de passageiros transportados.

Cada um dos sete ministérios atualmente atendidos, possui um setor de transporte, para gerenciar a frota permitida de 11 veículos e para solicitar à CVO o atendimento aos servidores do seu ministério. Para usar os serviços da CVO é preciso seguir o seguinte roteiro: 1 . o servidor solicita o veículo ao setor de transporte de seu órgão; 2. a telefonista de atendimento da CVO checa o código de controle, preenche o formulário próprio e a requisição de transporte, indicando local de saída e destino do funcionário e o número de servidores que serão transportados; 3 o rádio-operador contata o veículo em trânsito mais próximo do local de atendimento e transmite a autorização; 4. o motorista do veículo contatado preenche um formulário de controle e parte para atender o serviço solicitado; 5. executado o serviço, o veículo retorna à CVO (veja quadro).
A grande estratégia da CVO para reduzir a quilometragem e os gastos - além da redução da frota - está em que o transporte a cada chamada individual não corresponda necessariamente ao deslocamento de um novo veículo. O motorista só pode esperar o servidor até 10 minutos. todos os 42 motoristas da Central, que foram requisitados dos sete ministérios quando da redução de suas frotas, foram devidamente treinados pela FUNCEP para garantir a cordialidade, segurança e rapidez no atendimento.

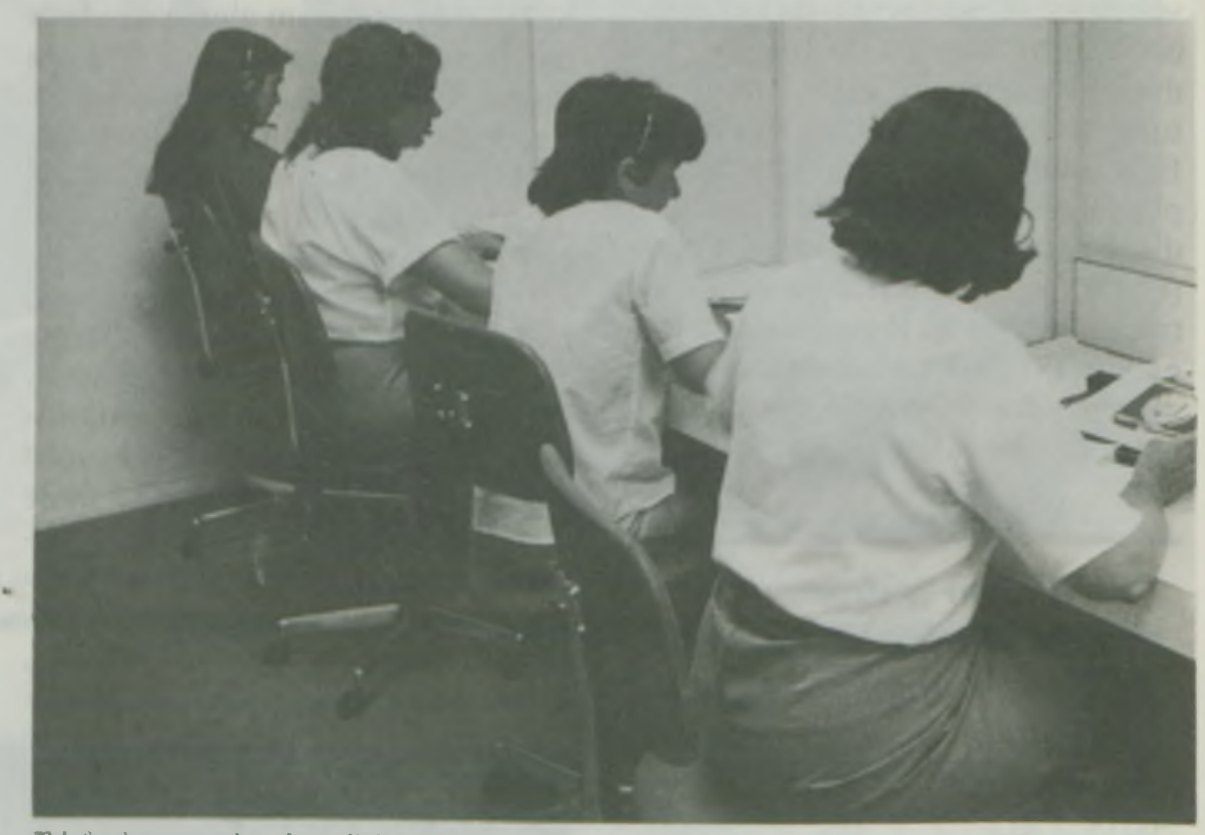

Telęfomiszas reçetrendo solicitaçào de veiculos à CVO.

AHAD ARSC - CNO

IRANSPOKIE DI PESSOAL E SERVICOS

ANALIF COMPARATINA

\begin{tabular}{|c|c|c|c|c|}
\hline ITEM & JAN $/ 88(A)$ & JUN/88 (B) & $\mathrm{JUN} / 88(\mathrm{C})^{*}$ & $\begin{array}{c}\text { REDUÇÃO A- } \\
(B+C)\end{array}$ \\
\hline FROTA & 207 & 40 & 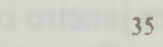 & 132 \\
\hline QUILOMETRAGEM & 269.994 & 43.436 & 45.651 & 180.907 \\
\hline MOTORISTAS & 273 & 42 & 46 & 185 \\
\hline CUSTO) (C's) & $25.7+6.126$ & 2.201 .822 & 4.353 .209 & 19.191.109 \\
\hline & \multicolumn{3}{|c|}{ Reduçào de Ciastos $\left(\sigma^{\circ}\right)$ : $A \cdot B+C=74,5 \%$} & \\
\hline
\end{tabular}

* inciUsão da frota d) SERviços

IONII: LLDDUP SI Y (10 


\section{NOTICIÁRIO}

\section{Todos os dias 10 requisições} são escolhidas aleatoriamente e checadas uma a uma

\section{REPERCUSSÃO}

Além do relatório sobre o desempenho da CVO durante o mês de junho enviado ao ministro Aluizio Alves, os órgãos atendidos recebem relatório mensal da CVO com todos os serviços prestados (veja quadro).

Para garantir o controle e o aprimoramento do serviço, todos os dias 10 requisições são escolhidas aleatoriamente e chegadas uma a uma pela telefonista, através do contato pessoal com o serviço atendido. Assim, é possivel constatar a qualidade e a pontualidade do transporte, a cordialidade e perícia do motorista e o levantamento de sugestōes.
A repercussão do desempenho da CVO pode ser medida pelo grande número de manifestações oficiais de apoio que vem recebendo, além de inúmeros pedidos de inclusão de órgãos federais ainda não integrados nessa primeira etapa. Animado com os resultados, o ministro Aluízio Alves comenta: "Além da grande eco- nomia que já conseguimos, estamos assegurando a mudança de mentalidade do servidor público em Brasília que está sendo atendido pela $\mathrm{CVO}$, que já não pede mais condução para pagar suas contas. Todos os usuários da CVO têm hoje a consciência de que a racionalização trabalha a seu favor, e não contra ele".

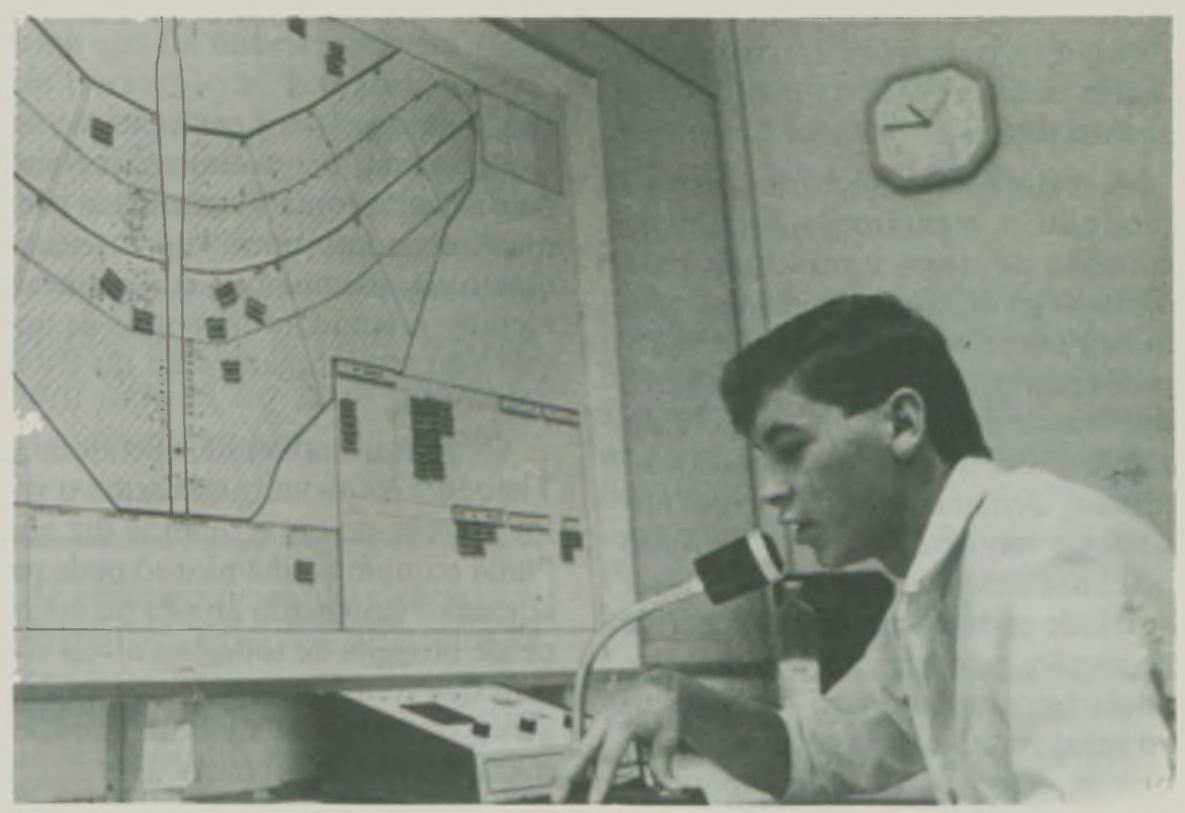

Rádio-operador conlala veiculo para execução de serviço.

SEDAP/SESC - CVO

FLUXOGRAMA GERAL DE FUNCIONAMENTO

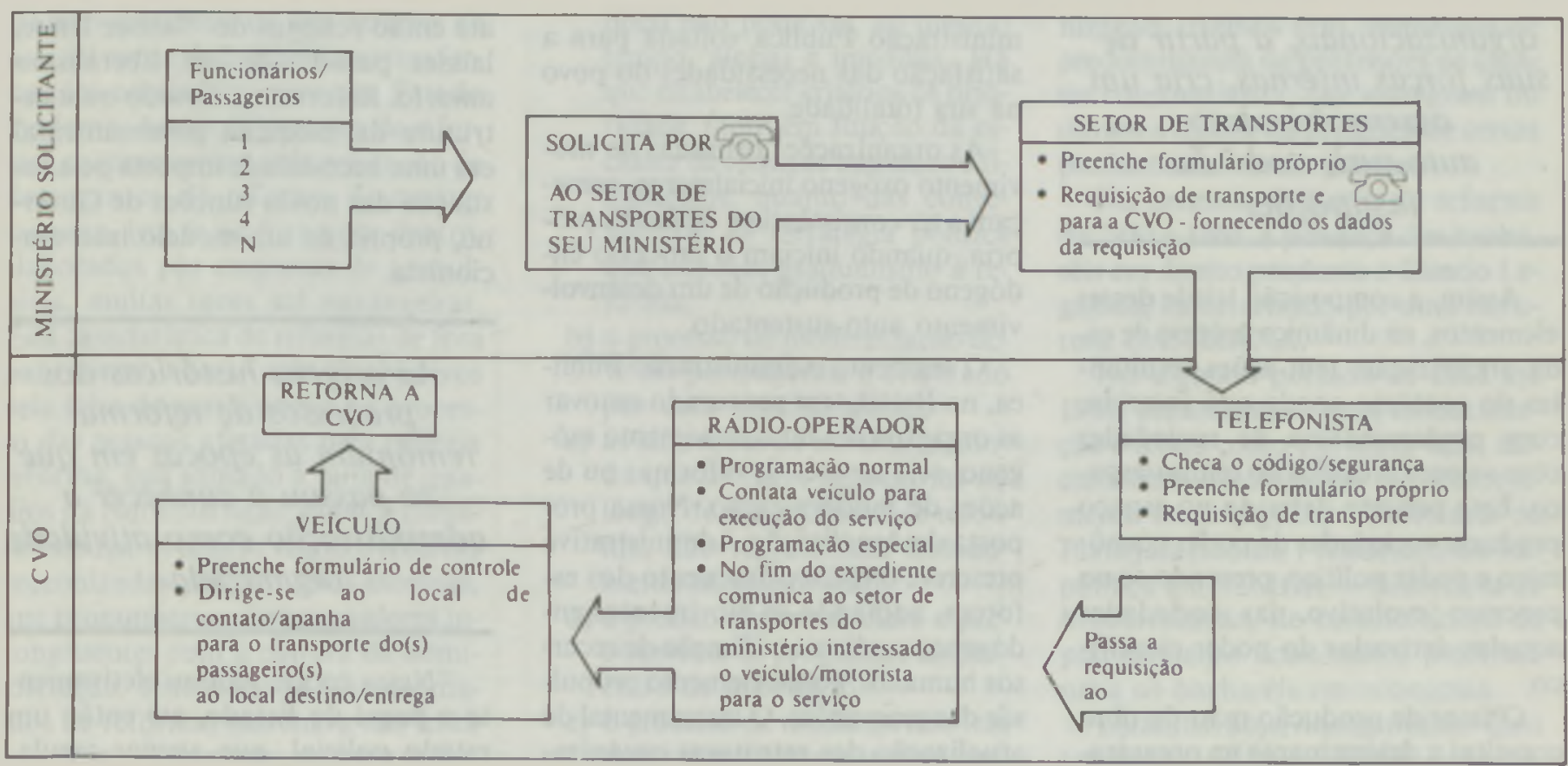

